\title{
Total anomalous pulmonary venous connection (surgical technique, early and late results) ${ }^{1}$
}

\author{
GIUSEPPE DI EUSANIO², FRANCIS A. SANDRASAGRA, RAYMUND J. DONNELLY, \\ AND DAVID I. HAMILTON
}

From the Cardiothoracic Surgical Unit, Royal Liverpool Children's Hospital, Liverpool L7 7DG

Di Eusanio, G., Sandrasagra, F. A., Donnelly, R. J., and Hamilton, D. I. (1978). Thorax, 33, 275-282. Total anomalous pulmonary venous connection (surgical technique, early and late results). Between March 1970 and October 1977, 36 patients underwent correction of total anomalous pulmonary venous connection. The ages ranged from 5 days to 16 years; 27 (75\%) were under 1 year and 19 were under 3 months of age at the time of surgery. The overall mortality was $33 \%$. Supracardiac connection was the commonest type and was associated with the lowest hospital mortality $(30 \%)$. The highest mortality occurred in the mixed and infracardiac types and was related in part to the presence of associated intracardiac anomalies. The use of hypothermia and circulatory arrest in infancy has resulted in a considerably lower hospital mortality compared with cases operated on under conventional cardiopulmonary bypass. The mortality in 23 infants (under 1 year of age) was $26 \%$ using circulatory arrest and was lowest when correction was performed within the first three months of life (18\%). All four infants operated on with standard cardiopulmonary bypass died, whereas this technique was found to be safe in older children. The surgical technique using a left anterolateral thoractomy with a trans-sternal extension is described. This technique gives an excellent exposure for fashioning a long anastomosis and has been associated with a low incidence of postoperative pulmonary complications. There have been no late deaths and all survivors, who are in excellent condition up to seven years after correction, have a normal exercise tolerance.

Total anomalous pulmonary venous connection (TAPVC) is a rare congenital anomaly. The incidence at birth has been reported as varying from 1 to $4 \%$ of all cases of congenital heart disease (DuShane, 1956; Keith et al., 1967; Jensen and Blount, 1971).

The natural history of the disease is unfavourable and less than $10 \%$ of patients survive the first year of life without surgical correction (Gathman and Nadas, 1970). Lewis et al. (1956) reported the first surgical success using hypothermia and inflow occlusion, and Cooley and Ochsner (1957) reported the first successful surgical repair using cardiopulmonary bypass. The history of the treatment of this defect can be divided into three eras (Engle, 1972). The first was the age of definition, classification (Brody 1942; Darling et al.,

${ }^{1}$ Supported by a grant from the National Heart Research Fund 'Present address: Div. Chirugia Cardiovascolare, Istituto Cardiologico 'G.M. Lancisi', Via Baccarani 6, Ancona, Italy
1957), and early attempts at correction (Muller, 1951; Burroughs and Kirklin, 1956). The second period (1960-70) was the age of precise diagnosis, with complete clinical, physiological, haemodynamic, and angiographic assessment (Cooley et al., 1966). The third era, which extends from 1970 to the present day, has been characterised by continuing improvement in the results of early total surgical correction.

We now review our experience in the management of this condition during the third era.

\section{Patients}

In the period March 1970 to October 1977, 36 patients with TAPVC underwent total correction at the Royal Liverpool Children's Hospital.

There were 19 boys and 17 girls whose ages ranged from 5 days to 16 years. The patients were divided into four groups according to the anatomical type of defect (Fig. 1). 


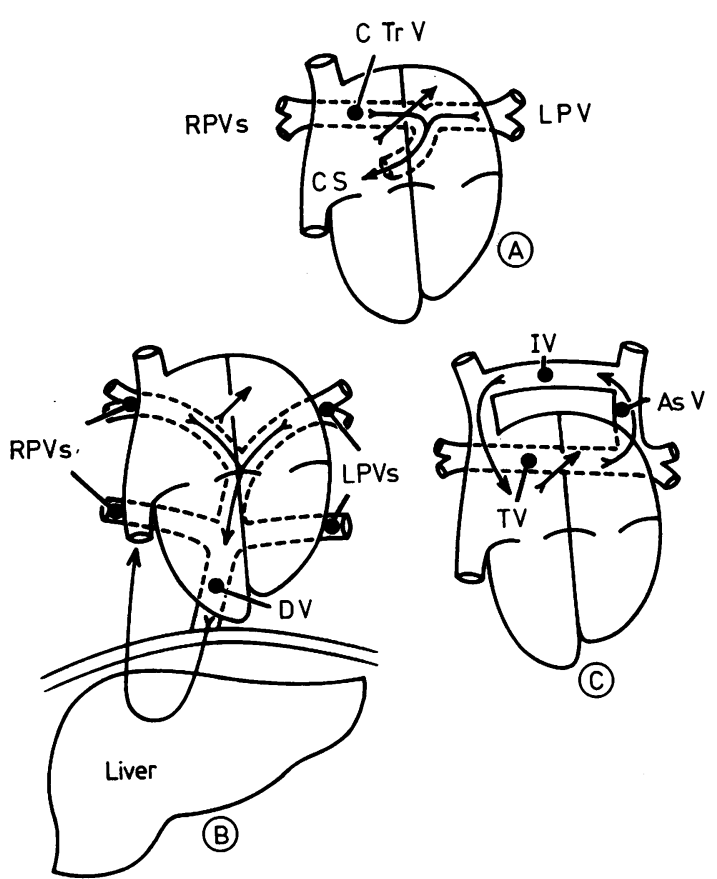

Fig. 1 Schematic representation of common variations of TAPVC. A: Cardiac type-right and left pulmonary veins (RPV-LPV) enter common transverse vein (CTrV), which drains into coronary sinus (CS). Direction of pulmonary blood flow and right to left interatrial shunt is indicated.

$B$ : Infracardiac type-pulmonary veins (RPVs $L P V s)$ drain into anomalous descending vein $(D V)$ behind pericardium, which passes through diaphragm to enter portal circulation. C: Supracardiac type-pulmonary veins drain into transverse vein (TV) behind heart. This joins wide ascending anomalous vein $(A s V)$, which drains into innominate vein (IV).

SUPRACARDIAC TAPVC

Supracardiac TAPVC was the commonest type $(64 \%)$. There were 23 patients in this group, 12 boys and 11 girls whose ages at operation ranged from 21 days to 16 years. Seventeen $(74 \%)$ were under 1 year of age (mean 88 days). Three were between 1 and 2 years (mean 15 months), and three were over 4 years (mean 8.5 years).

All the patients were symptomatic at the time of operation. Cyanosis, either at rest or on exercise, and cardiac failure were present in $77 \%$. Patients over 1 year of age were prone to respiratory infections. One patient had associated pulmonary stenosis. The pulmonary artery systolic pressure was over $60 \mathrm{mmHg}$ in $27 \%$.

Standard cardiopulmonary bypass was used in three infants (initial experience) and in the three children over 4 years of age. Seventeen patients underwent total correction using profound hypothermia induced by core cooling and circulatory arrest (Hamilton et al., 1973).

INPRACARDIAC (SUBDIAPHRAGMATIC) TAPVC

There were three boys and two girls in the infracardiac subdiaphragmatic TAPVC group (14\%). The ages ranged from 5 days to 5 months (mean 46 days). One patient had transposition of the great vessels and a complete atrioventricular canal.

A preductal coarctation and pronounced hypoplasia of the left heart chambers were present in another. All five patients were in cardiac failure and were cyanosed. The pulmonary artery pressure was above systemic pressure in all cases. The presence of TAPVC was discovered at the time of repair of an associated coarctation in one case. An attempt at complete repair of the coarctation and the anomalous venous connection using standard cardiopulmonary bypass failed in this patient. The others were operated on using profound hypothermia and circulatory arrest.

\section{CARDIAC TAPVC}

In the cardiac TAPVC group of four cases $(11 \%)$ the sex distribution was equal. All were in cardiac failure. One patient was cyanosed. Pulmonary valve stenosis was present in one case, and a common atrium with clefts in both atrioventricular valves, anomalous systemic venous connection, and pulmonary stenosis were found in another patient. Standard cardiopulmonary bypass was used in a 13-year-old girl and circulatory arrest in the three infants.

\section{MIXED TYPE}

Four patients (11\%) (two boys and two girls) had the mixed type of pulmonary venous connection. $\frac{T}{0}$ Two patients were less than 2 months old (mean 31 days), one was 34 months and the other $\widetilde{N}$ 8 years. One case had a mixture of supra and $N$ infracardiac anomalous pulmonary venous con- $N$ nection. In three cases cardiac and supracardiac $\frac{\omega}{\sigma}$ connections were present.

Cor triatriatum was present in two cases. Cyanosis and cardiac failure were present in all.

\section{Surgical technique}

The method of perfusion-induced profound hypo- $\frac{\stackrel{\rho}{\Phi}}{\overparen{D}}$ thermia and circulatory arrest employed at The $\varrho$ Royal Liverpool Children's Hospital since 1970 ? has been described (Hamilton et al., 1973). Easy 8 access to the oblique sinus behind the left atrium 
and the anterior aspect of the anomalous pulmonary venous connection is essential for fashioning a long anastomosis between these structures. The avoidance of undue trauma to the heart and lung by retraction and handling is an important consideration in infant surgery. A left anterolateral thoracotomy through the fourth intercostal space with trans-sternal extension gives excellent exposure to the two areas of the heart mentioned above. The infant is positioned on the operating table in a semi-recumbent position with the left shoulder and buttock raised on a small sandbag (Fig. 2).

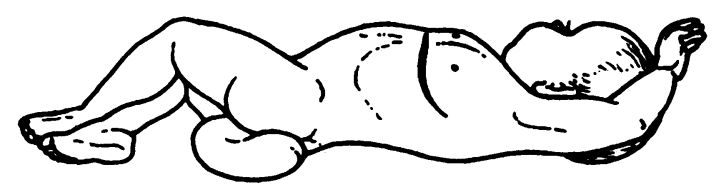

Fig. 2 Position of patient and thoracotomy incision (left anterolateral with trans-sternal extension).

The thoracotomy incision extends from the left mid-axillary line across the sternum for 2 to $3 \mathrm{~cm}$. The internal mammary vessels are ligated and divided. The sternopericardial ligament and thymus are dissected off the upper pericardium, which is opened just enough to allow cannulation of the right atrial appendage and the ascending aorta. The heart is thus not disturbed within the pericardial sac, and ventricular fibrillation due to distortion of the coronary arteries should not occur. Once cardiopulmonary bypass with cooling has been established, the pericardium is opened widely, the venae cavae are isolated in tape snares, and the anomalous pulmonary venous connection is identified. During the cooling period, the ductus arteriosus (if patent) is ligated, and the ascending vein is isolated and occluded in a snare. Both these measures are essential for the prevention of air embolism. Once the required nasopharyngeal temperature $\left(18-20^{\circ} \mathrm{C}\right)$ has been reached, the perfusion is stopped and the input line is clamped close to the patient. The ascending aorta and main pulmonary artery are occluded in a single vascular clamp above their valves to prevent air entering the great vessels. Blood is drained out of the patient into the heart-lung machine through the venous line, which is then occluded. The venae cavae are snared. The surgeon now takes up his position on the left side of the operating table. The first assistant (on the right) lifts the heart towards himself exposing the posterior aspect of the left atrium and the oblique sinus to the surgeon. The left atrium is freed from its attachment to the posterior pericardium near the mid-line over the right pulmonary veins as they enter the anomalous venous connection. A long incision is made into the posterior wall of the left atrium, and this is extended from the appendage as far as the atrial septum medially. The atrial septal defect or patent foramen ovale is sutured through this incision. In the supracardiac variety of drainage a similar incision (Fig. 3 ) is made in the anterior wall of the transverse common pulmonary vein. The margins of the two incisions are approximated with a continuous suture, except in the final centimetre where interrupted sutures are placed to allow subsequent growth. A vent is inserted into the apex of the left ventricle and air is expelled from this chamber during rewarming. The anomalous venous connection is ligated when the cardiac action is stable.

In the infradiaphragmatic variety, a ' $Y$ ' incision (Fig. 4) is made into the two upper lobe pulmonary veins and descending stem of the anomalous connection to allow a larger anastomosis. This wide opening is anastomosed to the left atrium in the same way. The two inferior pulmonary veins usually join the anomalous trunk well below the superior veins. Special care must, therefore, be taken to avoid placing the ligature proximal to the inferior pulmonary veins. In the cardiac and mixed type the approach is through a median sternotomy and right atriotomy. The anatomy of the pulmonary veins and atria is studied carefully. Particular attention is directed towards the coronary sinus, which may receive anomalous pulmonary veins, to the disposition of the atrial septum, and to any defect within that partition. It may be necessary to enlarge the coronary sinus before inserting a patch of pericardium or Dacron over its orifice. The patch is continued superiorly to provide a new atrial septum (Fig. 5). This will direct the pulmonary veins to the left atrium. In some cases extensions of the patch are necessary to cover the orifices of anomalous veins that enter the right side of the right atrium.

Anomalous pulmonary venous drainage to the right superior vena cava requires division of the anomalous vein close to the superior vena cava and reanastomosis to the left atrium.

\section{Results}

The overall hospital mortality for the entire group was $33 \%$. Twenty-three patients under 1 year of age underwent correction using profound hypothermia and circulatory arrest with six deaths 


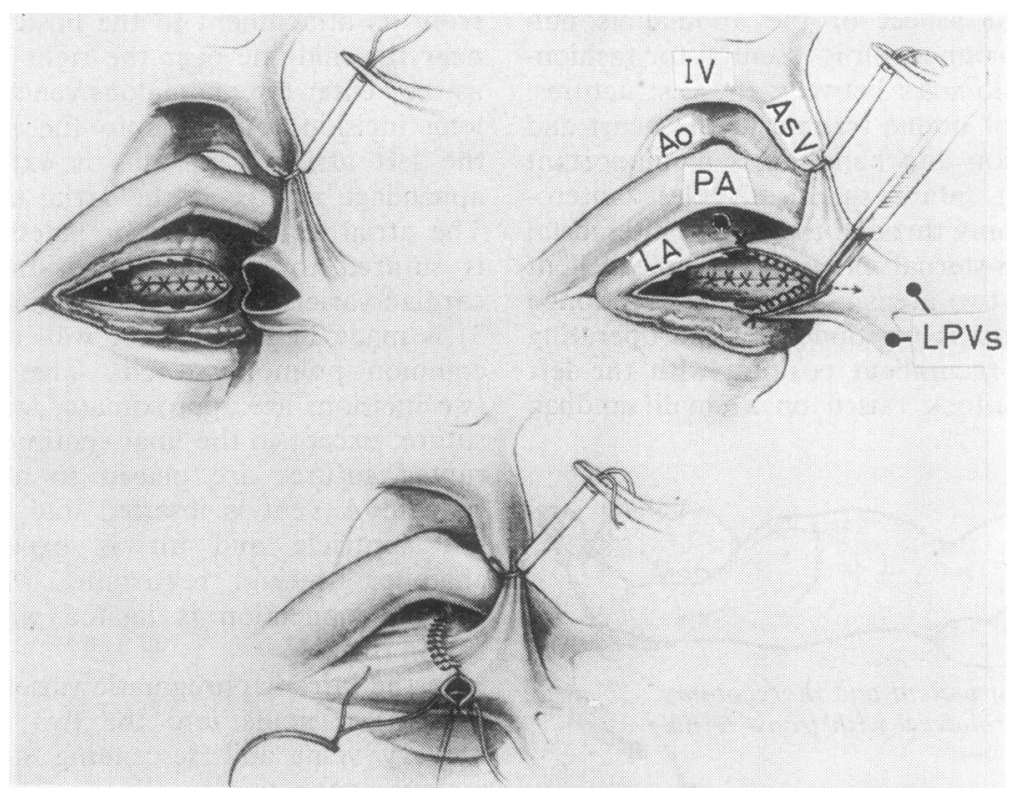

Fig. 3 Surgical technique for correction of supracardiac type of TAPVCapproach is through left anterolateral thoracotomy with trans-sternal extension. Posterior aspect of left atrium and oblique sinus is exposed. Long incision is made in left atrium $(L A)$ and in transverse anomalous vein. Atrial septal defect is closed, and anastomosis between left atrium and anomalous vein is fashioned. Ascending anomalous vein $(A s V)$ is ligated. $I V=$ innominate vein; $A o=$ aorta; $P A=$ pulmonary artery; $L P V S=l e f t$ pulmonary veins).

$(26 \%)$. Standard cardiopulmonary bypass was used in four other infants early in our experience, who all died. No deaths occurred using standard cardiopulmonary bypass in patients over the age of 2 years (Table 1).

\section{SUPRACARDIAC TYPE}

The hospital mortality for this group was $30 \%$ (Fig. 6). There were no deaths in the three patients over 2 years of age. Three infants who underwent surgery using standard cardiopulmonary bypass died. Two of these deaths were due to operative haemorrhage from the anastomosis, and the third was caused by cerebral haemorrhage.

Circulatory arrest was used in 17 cases with four deaths $(23 \%)$. Pulmonary infarction and cerebral damage accounted for three of the deaths. Both cerebral deaths were due to air-embolism resulting from faulty technique and were, therefore, avoidable. The fourth patient who died had anomalous pulmonary venous drainage to the superior vena cava, severe pulmonary hypertension $(90 \mathrm{mmHg}$ systolic), and relative hypoplasia of the left heart chambers. He had persistent low cardiac output

Table 1 Mortality in relation to age and perfusion technique

\begin{tabular}{|c|c|c|c|c|c|c|}
\hline Age & No. of patients & $C P B P$ & Mortality & $C A$ & Mortality & Overall mortality \\
\hline $\begin{array}{l}\text { Under } 3 \text { months } \\
3-12 \text { months }\end{array}$ & $\begin{array}{r}19 \\
8\end{array}$ & $\begin{array}{l}2 \\
2\end{array}$ & $\begin{array}{l}2 \\
2\end{array}$ & $\begin{array}{r}17 \\
6\end{array}$ & $\begin{array}{l}3(18 \%) \\
3(50 \%)\end{array}$ & \\
\hline \multicolumn{2}{|c|}{ Total under 1 year 27} & 4 & $4(100 \%)$ & 23 & $6(26 \%)$ & $10(37 \%)$ \\
\hline $\begin{array}{l}\text { 12-24 months } \\
2-16 \text { years }\end{array}$ & $\begin{array}{l}3 \\
6\end{array}$ & $\overline{6}$ & $\overline{0}$ & $\frac{3}{-}$ & $2(67 \%)$ & \\
\hline Total & 36 & 10 & 4 & 26 & 8 & $12(33 \%)$ \\
\hline
\end{tabular}

CPBP $=$ Standard cardiopulmonary bypass; $C A=$ Profound hypothermia and circulatory arrest. 
after total correction (Table 2). Two survivors developed convulsions in the postoperative period, but seven years later only one of them still re-

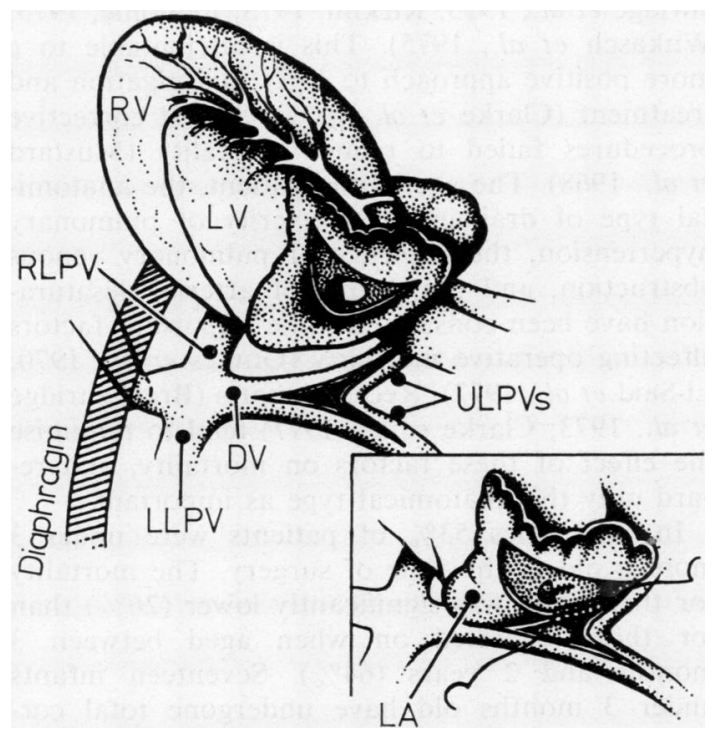

Fig. 4 Surgical technique for correction of infracardiac type of TAPVC. Approach is through left anterolateral thoracotomy with trans-sternal extension. Long incision is made into posterior wall of left atrium $(L A)$ extending from appendage to interatrial septum medially. Atrial septal defect or patent foramen ovale is closed. ' $Y$ ' incision is made into two upper lobe pulmonary veins (ULPVS) extending inferiorly into descending anomalous vein (DV). Anastomosis is made, and anomalous vein is ligated below entry of lower lobe pulmonary veins ( $R L P V$ and $L L P V)$.

$R V=$ right ventricle; $L V=$ left ventricle. quires anticonvulsant drugs. There was one instance each of paralysis of the left hemidiaphragm, collapse of the left lung, and sinus bradycardia. The last patient still has first-degree heart-block but is asymptomatic.

One patient developed pulmonary oedema, which responded to diuretic therapy. Radiological evidence of pulmonary venous congestion is common, but this has always regressed after a period of intermittent positive-pressure ventilation with positive end-expiratory pressure and diuretic therapy. At follow-up from four months to seven years (mean four years), 14 of the 15 survivors are in excellent health.

\section{CARDIAC TYPE}

One of the four patients in this group died as a result of pulmonary oedema (Table 2). The three survivors are well (mean follow-up one year three months).

Table 2 Causes of death in the supracardiac and cardiac types of TAPVC

\begin{tabular}{lll}
\hline Anatomical type & No. of patients & Cause of death \\
\hline Supracardiac & 2 & $\begin{array}{l}\text { Haemorrhage } \\
\text { Extensive infarction right } \\
\text { lung }\end{array}$ \\
& 1 & $\begin{array}{l}\text { Cerebral haemorrhage } \\
\text { Low cardiac output } \\
\text { (hypoplastic left heart } \\
\text { chambers) } \\
\text { Cerebral air embolism } \\
\end{array}$ \\
& 1 & Pulmonary oedema \\
\hline
\end{tabular}

INFRACARDIAC TYPE

Two of the five patients in this group died. Both presented early in our experience, and both had

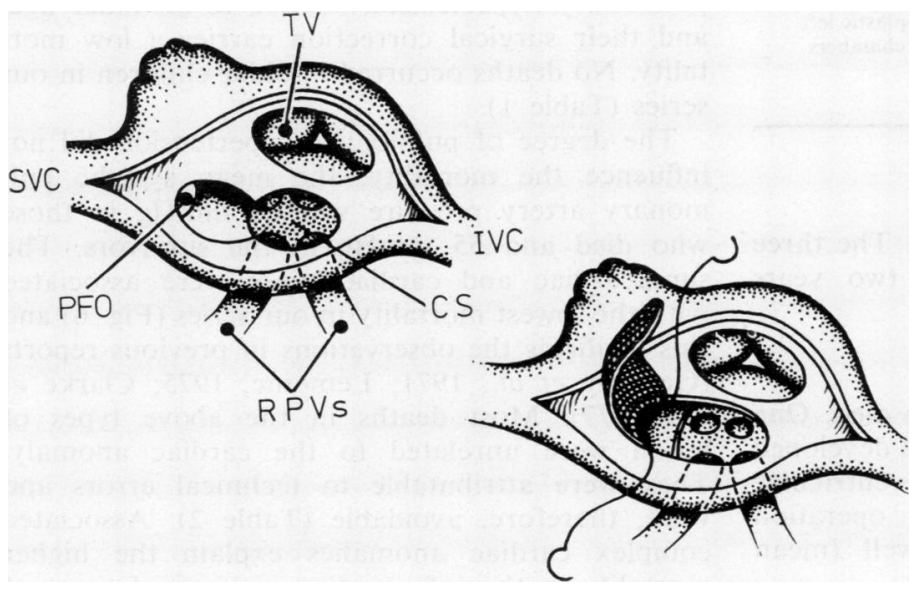

Fig. 5 Surgical technique for correction of cardiac (coronary sinus) type of TAPVC. Approach is through median sternotomy and right atriotomy. Part of atrial septum between coronary sinus (CS) and patent foramen ovale (PFO) or atrial septal defect (if present) is excised and a Dacron patch inserted to direct pulmonary venous return to left atrium. $S V C=$ superior vena cava $; \boldsymbol{I V C}=$ inferior vena cava; $T V=$ tricuspid valve; $R P V S=$ right pulmonary veins. 


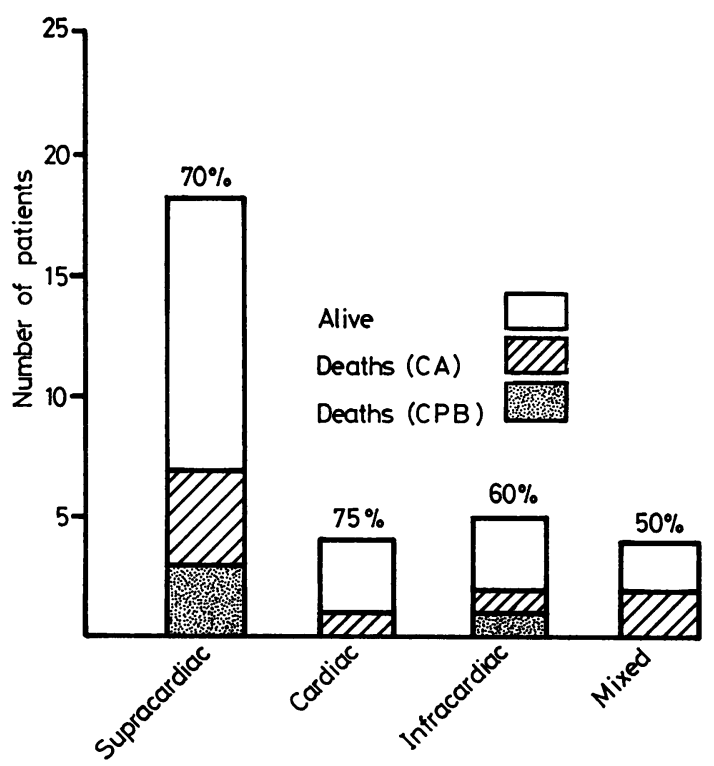

Fig. 6 Mortality in relation to anatomical type of anomalous connection.

$C P B=$ standard cardiopulmonary bypass; $C A=$ profound hypothermia and circulatory arrest.

Table 3 Causes of death and associated anomalies in the infracardiac and mixed types of TAPVC

\begin{tabular}{llll}
\hline Anatomical type & $\begin{array}{l}\text { No. of } \\
\text { patients }\end{array}$ & $\begin{array}{l}\text { Cause of } \\
\text { death }\end{array}$ & $\begin{array}{l}\text { Associated } \\
\text { anomalies }\end{array}$ \\
\hline Infracardiac & 1 & $\begin{array}{l}\text { Low cardiac } \\
\text { output }\end{array}$ & $\begin{array}{l}\text { Transposition of } \\
\text { great vessels and } \\
\text { atrioventricular } \\
\text { canal } \\
\text { Coarctation of the } \\
\text { aorta +hypoplastic } \\
\text { left ventricle } \\
\text { Mypoplastic left } \\
\text { heart chambers }\end{array}$ \\
& 1 & $\begin{array}{l}\text { Low cardiac } \\
\text { output } \\
\text { Low cardiac } \\
\text { output } \\
\text { Ventricular } \\
\text { fibrillation }\end{array}$ & \\
\hline 1 & 1 & &
\end{tabular}

additional cardiac anomalies (Table 3 ). The three survivors are well (mean follow-up two years six months).

\section{MIXED TYPE}

Two of the four patients in this group died. One had hypoplastic left heart chambers and developed a low output state. The second died of ventricular fibrillation at the conclusion of the operation (Table 3). The two survivors are well (mean follow-up two years five months).

\section{Discussion}

The outlook for patients with TAPVC has changed dramatically in the past five to seven years (Breckenridge et al., 1973; Kirklin, 1973; Lemoine, 1975; Wukasch et al., 1975). This is attributable to a more positive approach to early investigation and treatment (Clarke et al., 1977). Staged corrective procedures failed to reduce mortality (Mustard et al., 1968). The age of the patient, the anatomical type of drainage, the severity of pulmonary hypertension, the presence of pulmonary venous obstruction, and the degree of arterial desaturation have been considered to be important factors affecting operative mortality (Gomes et al., 1970; El-Said et al., 1972). Recent reports (Breckenridge et al., 1973; Clarke et al., 1977) tend to minimise the effect of these factors on mortality, and regard only the anatomical type as important.

In this series $53 \%$ of patients were under 3 months old at the time of surgery. The mortality for this group was significantly lower $(26 \%)$ than for those operated on when aged between 3 months and 2 years (64\%). Seventeen infants under 3 months old have undergone total correction using profound hypothermia and circulatory arrest with a mortality of $18 \%$. This difference is partly because in our early experience we used standard cardiopulmonary bypass in a higher proportion of cases in the group aged from 3 months to 2 years (Table 1 ) and to the unfortunate fatal complication of cerebral air-embolism in two cases, which was avoidable. Clinical deterioration usually occurs, however, if conservative treatment is used in patients with severe pulmonary venous hypertension, and this in turn increases mortality when surgery is delayed.

A small group of children without significant pulmonary hypertension survive to an older age, and their surgical correction carries a low mortality. No deaths occurred in older children in our series (Table 1).

The degree of pulmonary hypertension did not influence the mortality; the mean systolic pulmonary artery pressure was $60 \mathrm{mmHg}$ in those who died and $55 \mathrm{mmHg}$ in the survivors. The supracardiac and cardiac types were associated with the lowest mortality in our series (Fig. 6) and this confirms the observations in previous reports (Gersony et al., 1971; Lemoine, 1975; Clarke et al., 1977). Most deaths in the above types of lesion were unrelated to the cardiac anomaly. They were attributable to technical errors and $\triangle$ were, therefore, avoidable (Table 2). Associated complex cardiac anomalies explain the higher 8 mortality in the infracardiac and mixed types of 
connections (Fig. 6 and Table 3).

Early diagnosis and complete surgical correction of TAPVC is yielding encouraging early results, which continue to improve with increasing experience. The mortality in this series has fallen from $67 \%$ to $22 \%$ in the past seven years (Fig. 7). The use of circulatory arrest has had a profound influence in reducing hospital mortality in infancy. All four infants who underwent surgery using standard cardiopulmonary bypass early in our experience died. Twenty-three patients under 1 year of age underwent correction using profound hypothermia and circulatory arrest with a mortality of $26 \%$. Standard cardiopulmonary bypass was satisfactory and safe in older children, and there was no mortality.

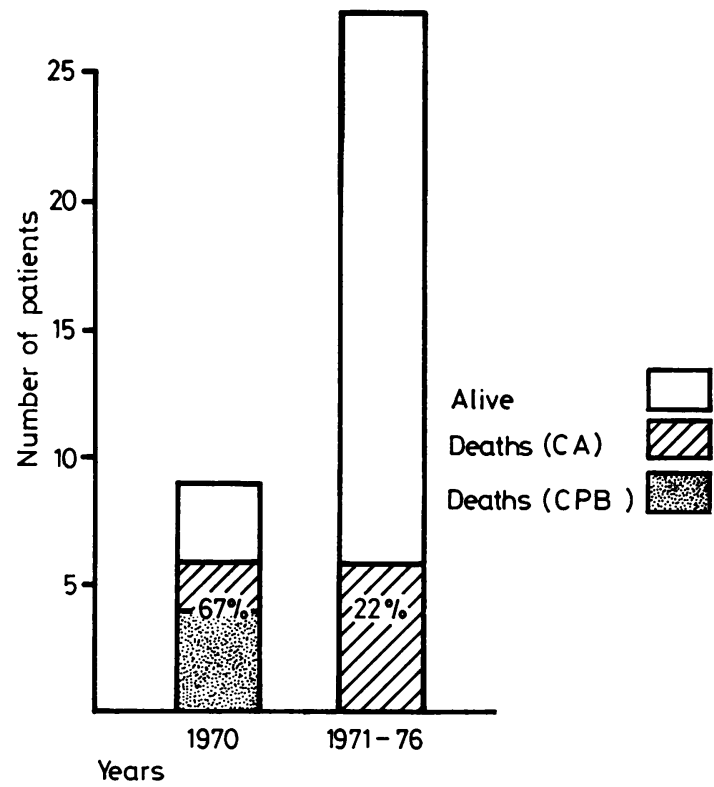

Fig. 7 Mortality in relation to early and recent experience. In four of six deaths of initial experience (1970) standard cardiopulmonary bypass (CPB) was used.

This surgical technique gives an excellent exposure for fashioning a long anastomosis and, in our experience, a low incidence of postoperative pulmonary complications. Pulmonary oedema was considered to be the cause of death in $86 \%$ of fatalities (Clarke et al., 1977). In our series this complication has caused concern in two patients only, one of whom died.

Our policy is to operate as soon as the diagnosis has been established regardless of the infant's age.
Early total correction has been justified by the excellent long-term clinical results in all survivors. Recent haemodynamic studies have shown normal cardiac function after surgical correction performed in infancy (Mathew et al., 1977), and add further support to this policy. A comparison of haemodynamic studies in patients who have undergone total correction at a later age, with those who have been corrected in infancy, is awaited with interest.

We wish to thank our colleagues in cardiology, radiology, anaesthesia, pathology, physiotherapy, nursing, and physics technology who have shared in the management of these infants.

\section{References}

Breckenridge, I. M., de Leval, M., Stark, J., and Waterston, D. J. (1973). Correction of total anomalous pulmonary venous drainage in infancy. Journal of Thoracic and Cardiovascular Surgery, 66, 447-453.

Brody, N. (1942). Drainage of the pulmonary veins into the right side of the heart. Archives of Pathology, 33, 221-240.

Burroughs, J. T., and Kirklin, J. W. (1956). Complete surgical correction of total anomalous pulmonary venous connection: Report of three cases. Proceedings of Staff Meetings of the Mayo Clinic, 31, 182-188.

Clarke, D. R., Stark, J., de Leval, M., Pincott, J. R., and Taylor, J. F. N. (1977). Total anomalous pulmonary venous drainage in infancy. British Heart Journal, 39, 436-444.

Cooley, D. A., and Ochsner, A. jun. (1957). Correction of total anomalous pulmonary venous drainage. Technical considerations. Surgery, 42, 1014-1021.

Cooley, D. A., Hallman, G. L., and Leachman, R. D. (1966). Total anomalous pulmonary venous drainage-correction with the use of cardiopulmonary bypass in 62 cases. Journal of Thoracic and Cardiovascular Surgery, 51, 88-101.

Darling, R. C., Rothney, W. B., and Craig, J. M. (1957). Total pulmonary venous drainage into the right side of the heart. Laboratory Investigation, 6, 44-64.

DuShane, J. W. (1956). Total anomalous pulmonary venous connection: Clinical Aspects. Proceedings of Staff Meetings of the Mayo Clinic, 31, 167-170.

El-Sajd, G., Mullins, S. E., and McNamara, D. G. (1972). Management of total anomalous pulmonary venous return. Circulation, 45, 1240-1250.

Engle, M. L. (1972). Total anomalous pulmonary venous drainage. Success story at last. Circulation, 46, 209-211.

Gathman, G. E., and Nadas, A. S. (1970). Total anomalous pulmonary venous connection. Clinical and physiologic observations of $\mathbf{7 5}$ pediatric patients. Circulation, 42, 143-154. 
Gersony, W. M., Bowman, F. C., Steeg, C. N., Hayes, C. J., Jesse, M. J., and Malm, J. R. (1971). Management of total anomalous pulmonary venous drainage in early infancy. Circulation, 43, Supplement I, $19-24$.

Gomes, M. M. R., Feldt, R. H., McGoon, D. C., and Danielson, G. K. (1970). Total anomalous pulmonary venous connection-surgical considerations and results of operation. Journal of Thoracic and Cardiovascular Surgery, 60, 116-122.

Hamilton, D. I., Shackleton, J., Rees, G. J., and Abbott, T. (1973). Experience with deep hypothermia in infancy using core cooling. Heart Disecise in Infancy, edited by B. G. Barratt-Boyes, J. M. Neutze, and E. A. Harris, pp. 52-58. Churchill Livingstone, Edinburgh.

Jenson, J. B., and Blount, S. G. (1971). Total anomalous pulmonary venous return. A review and report of the oldest surviving patient. American Heart Journal, 82, 387-407.

Keith, J. D., Rowe, R. D., and Vlad, P. (1967). Heart Disease in Infancy and Childhood, 2nd edition, p. 493. Macmillan Publishing Co., New York.

Kirklin, J. W. (1973). Surgical treatment for total anomalous pulmonary venous connection in infancy - Heart Disease in Infancy, edited by $\mathrm{B}$. G. Barratt-Boyes, J. M. Neutze, and E. A. Harris, p. 89. Churchill Livingstone, Edinburgh.
Lemoine, F. (1975). Retour veineux pulmonaire total anormal chez le nourisson. Traitement chirurgical Presented at 7th Riunioni Medico-Chirugiche Internazionali-Torino.

L.ewis, F. J., Varco, R. L., Taufic, M., and Niazi, S. A. (1956). Direct vision repair of triatrial heart and total anomalous pulmonary venous drainage. Surgery, Gynecology and Ostetrics, 102, 713-720.

Mathew, R., Thilenius, O. G., Replogle, R. L., and Arcilla, R. A. (1977). Cardiac function in total anomalous pulmonary venous return before and after surgery. Circulation, 55, 361-370.

Muller, W. H. (1951). The surgical treatment of transposition of the pulmonary veins. Annals of Surgery, 134, 683-693.

Mustard, W. T., Keon, W. J., and Trusler, G. A. (1968). Transposition of the lesser veins (total anomalous pulmonary venous drainage). Progress in Cardiovascular Diseases, 11, 145-155.

Wukasch, D. C., Deutsch, M., Reul, G. J., Hallman, G. L., and Cooley, D. A. (1975). Total anomalous pulmonary venous return. Review of 125 patients treated surgically. Annals of Thoracic Surgery, 19, 622-633.

Requests for reprints to: David I. Hamilton, MB, BS, FRCS, Royal Liverpool Children's Hospital, Myrtle Street, Liverpool L7 7DG. 